\title{
In-vitro comparison of hydroxyapatite coatings obtained by cold spray and conventional thermal spray technologies
}

\section{A.M. Vilardell ${ }^{\mathrm{a}, *}$}

amvilardell.research@gmail.com

N. Cinca

N. Garcia-Giralt

S. Dosta $^{\mathrm{a}}$

I.G. Cano $^{\mathrm{a}}$

$\mathrm{X}$. Nogués

J.M. Guilemany

${ }^{a}$ Centre de Projecció Tèrmica (CPT). Dpt. Ciència dels Materials i Química Física, Universitat de Barcelona Martí i Franquès 1, 08028, Barcelona, Spain

bIMIM (Institut Hospital del Mar d'Investigacions Mèdiques), CIBERFES, ISCIII, Doctor Aiguader 88, 08003, Barcelona, Spain

${ }^{*}$ Corresponding author.

Abstract

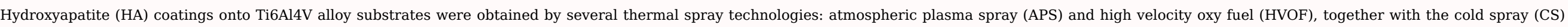

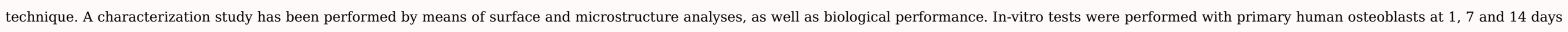

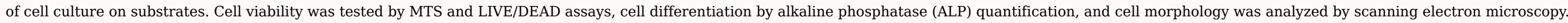

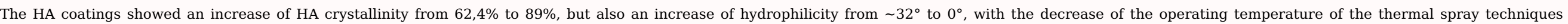

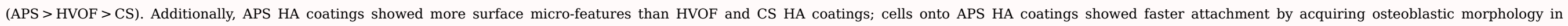

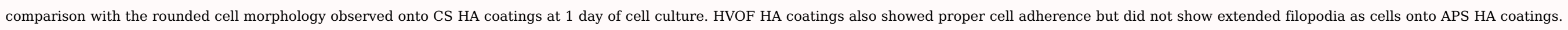


features but also moderate surface wettability whereas cell proliferation and differentiation is suggested to be highly influenced by HA crystallinity and crystal size.

Keywords: Atmospheric plasma spray; High velocity oxy fuel; Cold spray; Hydroxyapatite coatings; In-vitro tests; Joint prosthesis

\section{Introduction}

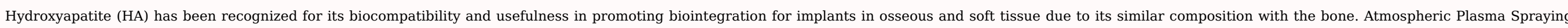

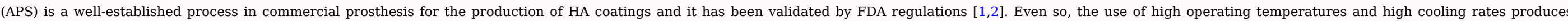

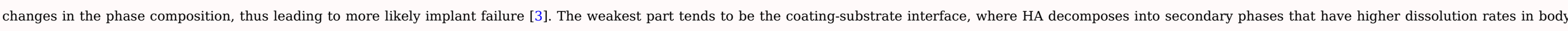
fluids, ending up with the delamination of the coating [1]


mechanical properties by the interlocking of bone ingrowth into the pores [4] 


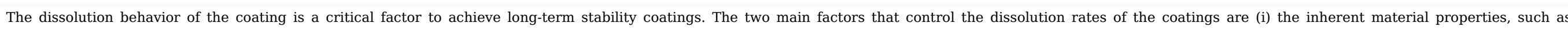

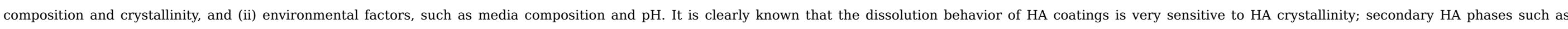

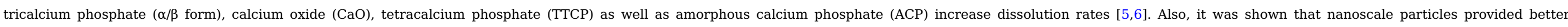

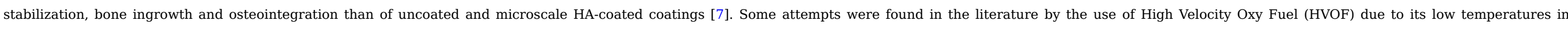





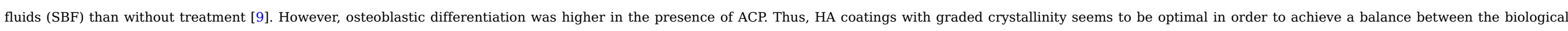
properties of the as-sprayed coatings and the adhesive strength of the crystalline coatings [10]

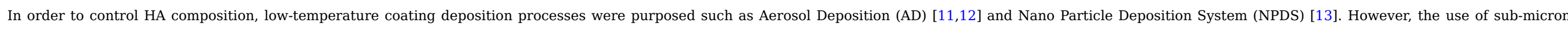

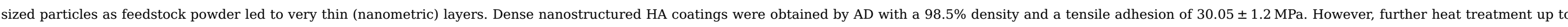

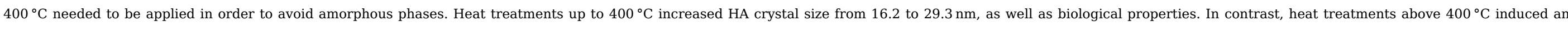



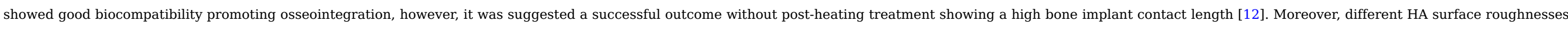

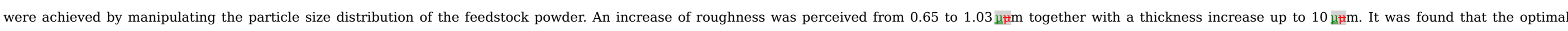
biological performance was for $5 \underline{\mu}$ m thick HA coating with an intermediate surface roughness of $0.82 \underline{\mu}$ 프 [15]



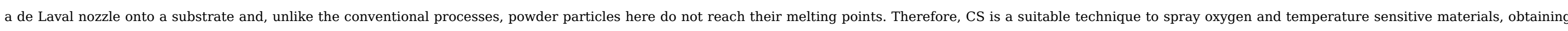

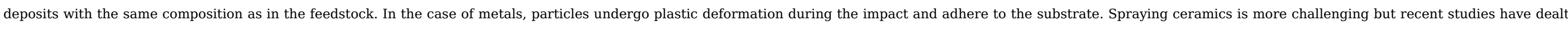


especially beneficial in biomedical field [20].

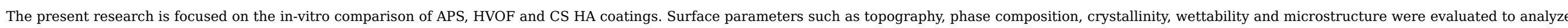
cell response.

\section{Materials and experimental method}

\subsection{Feedstock materials}

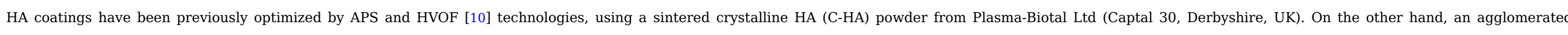

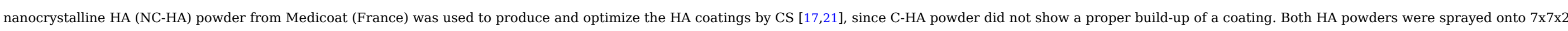
$\mathrm{mm}$ Ti6Al4 alloy substrates for the performance of the in-vitro tests.

\subsection{Deposition and characterization of coatings}

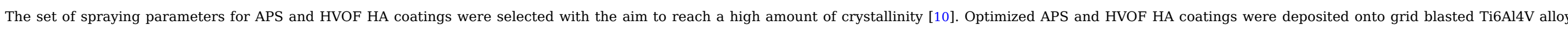

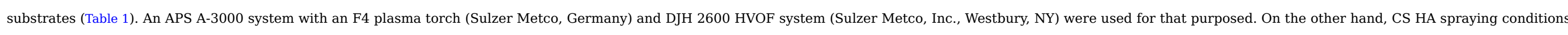

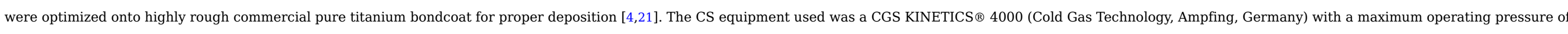
$40 \mathrm{bar}$, temperature of $800^{\circ} \mathrm{C}$ and it operated with nitrogen as the propellant gas.

Table 1 Optimal APS and HVOF spraying conditions [10 ${ }^{\mathrm{a}}$. 


\begin{tabular}{|c|c|c|c|}
\hline \multicolumn{2}{|c|}{ APS } & \multicolumn{2}{|c|}{ HVOF } \\
\hline Primary gas (Ar) [1 min-1] & 50 & Oxygen [1 min-1] & 193 \\
\hline Secondary gas (H2) [l min-1] & 1 & Hydrogen [l min-1] & 635 \\
\hline Carrier gas (Ar) [l min-1] & 3.6 & Air [1 min-1] & 275 \\
\hline Intensity [A] & 500 & Feeding rate $[\mathrm{g} \mathrm{s}-1]$ & 33 \\
\hline Stand off-distance $[\mathrm{mm}]$ & 80 & Stand off-distance & 225 \\
\hline Torch speed [mms-1] & 600 & Torch speed [mms-1] & 1000 \\
\hline Gun passes $\left[n^{\circ}\right]$ & 5 & Gun passes $\left[n^{\circ}\right]$ & 5 \\
\hline
\end{tabular}

a Spraying conditions of HA coatings by CS are summarized in the following intellectual property [21].

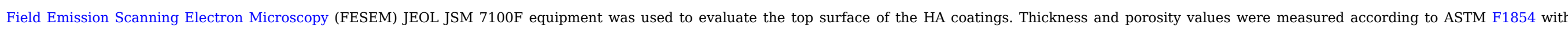

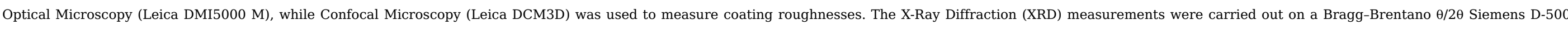




mode with $2 \mathrm{ml}$ volume Milli-Q $\mathrm{H}_{2} \mathrm{O}$ droplet.

\subsection{Cell culture}



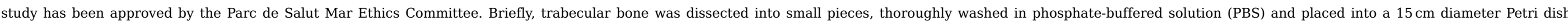

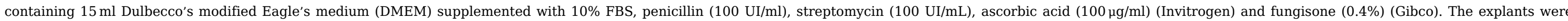

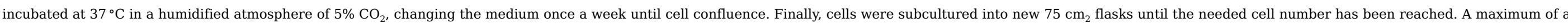

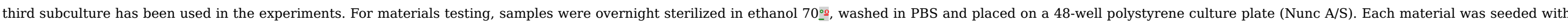

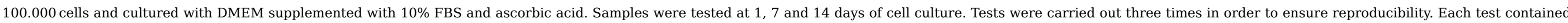

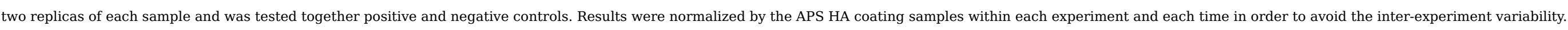

\subsection{Cell viability assays}

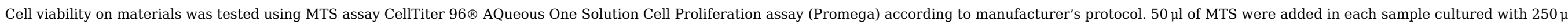
of medium, incubating for $3 \mathrm{~h}$ and then recording the absorbance at $490 \mathrm{~nm}$.

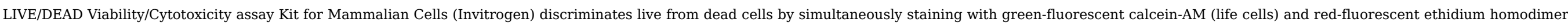

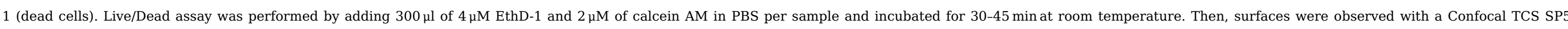
Upright from Leica Microsystems.

\subsection{Alkaline phosphatase assay}

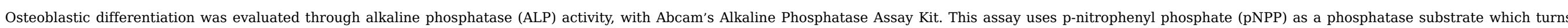
yellow when dephosphorylated (it turns to p-nitrophenol) by ALP. The resulting absorbance was measured at $405 \mathrm{~nm}$ using a scanning multi-well spectrophotometer.

\subsection{Cell morphology}

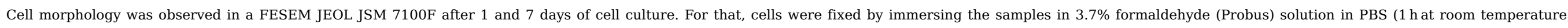





(x3) and 100\% (x3) of ethanol.

\subsection{Statistical analysis}

Statistical analyses were performed by Mann-Whitney $\underline{\underline{U}}$ test for group comparisons in the SPSS v.12.0 for Windows. All analyses were two-tailed, and p-values $<0.05$ were considered significant.

\section{Results}

\subsection{Surface characterization of HA coatings}


coating (Fig. 1C) shows a more regular surface as a result of the compaction of the particles [19].



a)



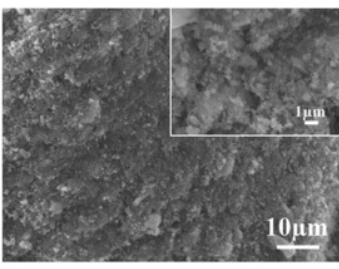

Fig. 1 FESEM micrographs of the top surface areas of a) APS, b) HVOF and c) CS HA coatings.

\section{alt-text: Fig. 1}

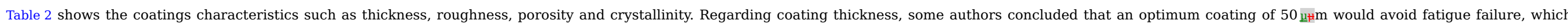

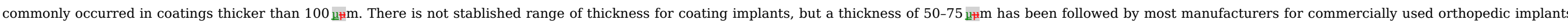

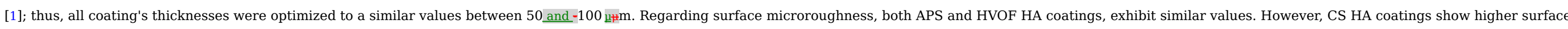





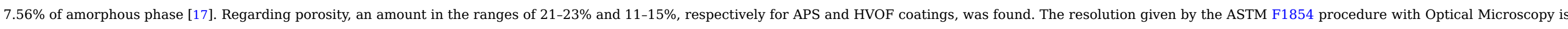
however too low to evaluate the porosity of the CS HA coatings; a more detailed study on its microstructure can be found in the previous study [16].

Table 2 Surface characterization of HA coatings obtained by APS and CS (*Nanoporosity).

alt-text: Table 2

\section{PROPERTIES}

Thickness $(\mu \mathrm{m})$

Microroughness Ra $(\mu \mathrm{m})$

Crystallinity (\%)

Porosity (\%)

\section{APS}

$84.5 \pm 6.1$
$5.8 \pm 0.4$
62.4

21-23

\section{HVOF}

$68.6 \pm 6.0$

$4.2 \pm 0.4$

$11-15$
CS

$45 \pm 20$

$12 \pm 1$

89

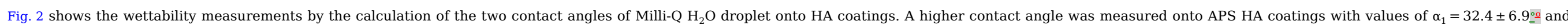








a)



b)

c)

Fig. 2 Contact angle of a Milli-Q $\mathrm{H}_{2} \mathrm{O}$ droplet a) APS, b) HVOF and c) CS HA coatings.

alt-text: Fig. 2

\subsection{Osteoblast viability and proliferation}

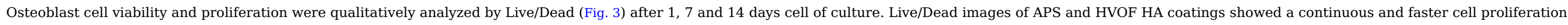

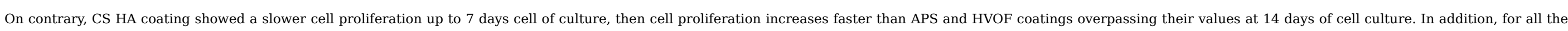
conditions, no significant number of dead cells was found along days of cell culture. Fig. 4 shows the MTS assay test, which corroborates quantitatively the results obtained with Live/Dead assay. 

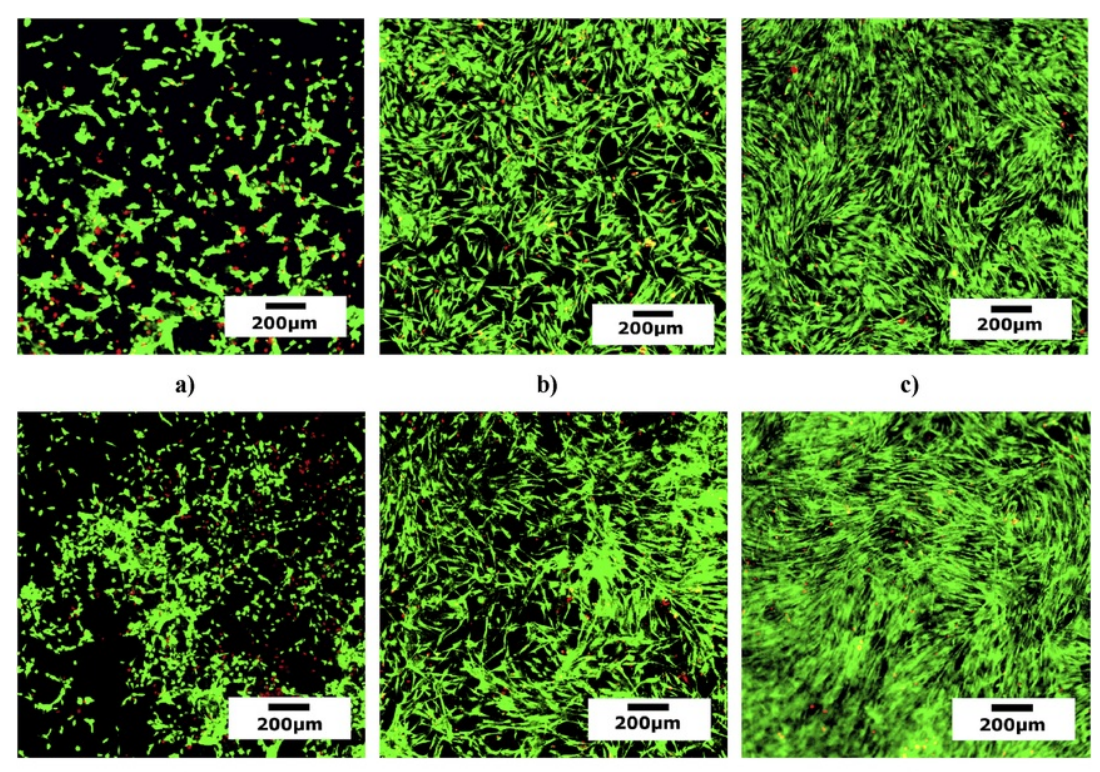

d)

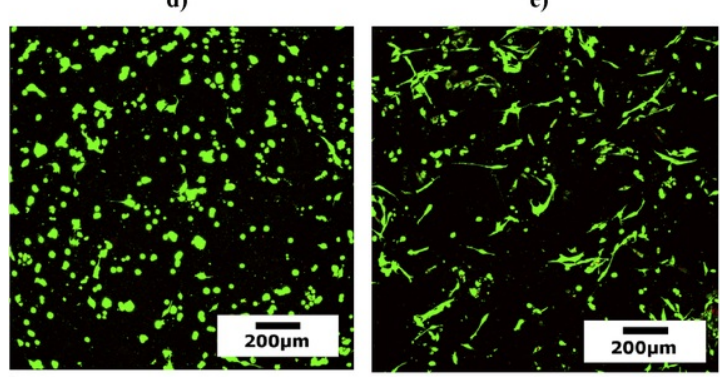

g)

h)

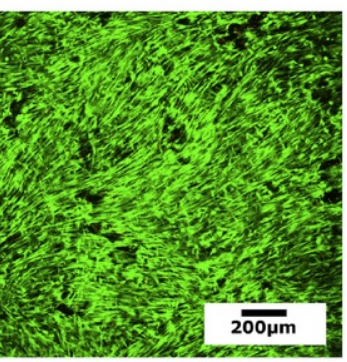

i)

Fig. 3 Live/Dead assay at 1, 7 and 14 days (from left to right) of cell culture onto a,b,c) APS, d,e,f) HVOF and g,h,i) CS HA coatings alt-text: Fig. 3

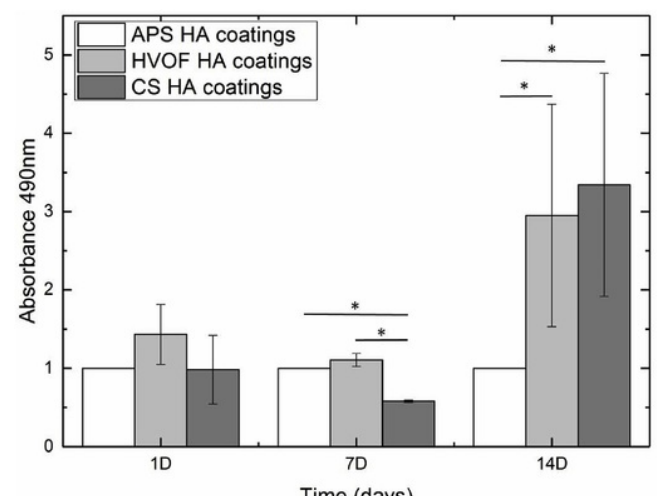

Fig. 4 MTS assay at 1, 7 and 14 days of cell culture onto APS, HVOF and CS HA coatings ( $n=3$; ${ }^{p}$-values $<0.05$ ). 


\subsection{Osteoblast differentiation}

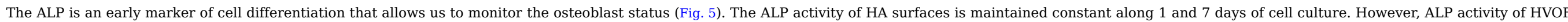
and CS HA coatings showed significantly higher values in comparison with APS HA coatings, especially HVOF HA coating.

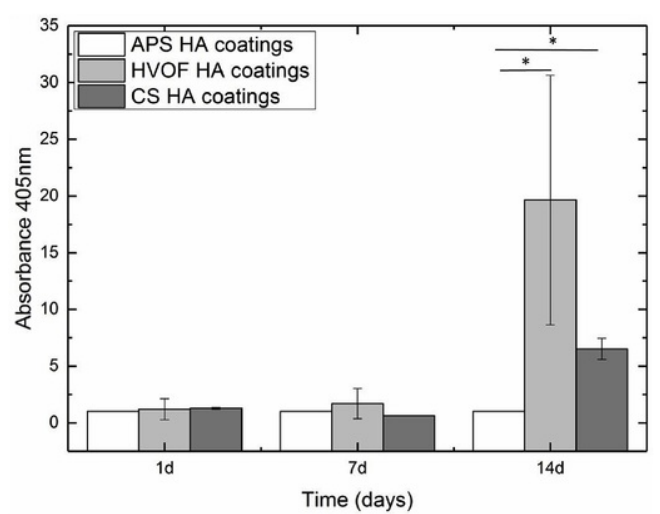

Fig. 5 ALP assay at 1,7 and 14 days of cell culture onto APS, HVOF and CS HA coatings $(n=3 ; *$-values $<0.05)$.

\section{alt-text: Fig. 5}

\subsection{Morphological aspects of osteoblast}

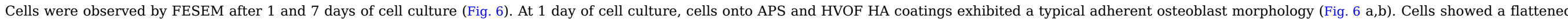

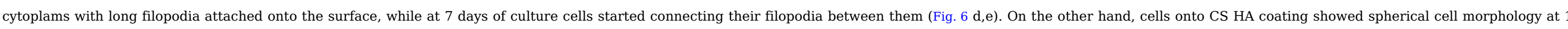

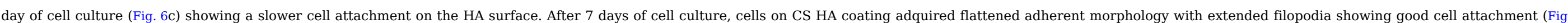
6f).
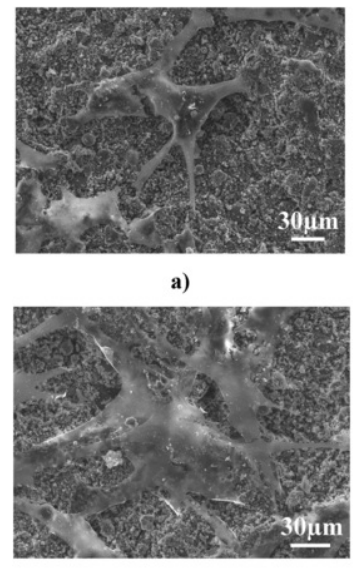

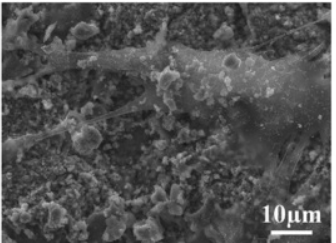

b)

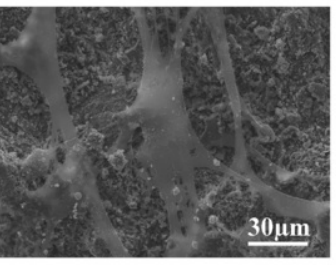

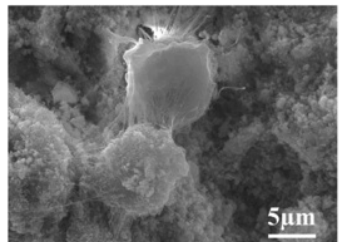

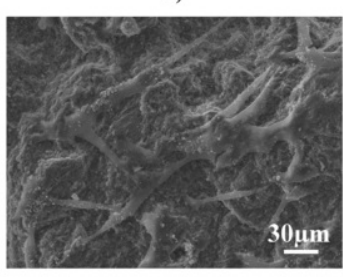

Fig. 6 FESEM micrographs of cells at a,b,c) 1 and d,e,f) 7 days of cell culture onto $(a, d)$ APS, (b,e) HVOF and (c,f) CS HA coatings $(n=3)$.

alt-text: Fig. 6 


\section{Discussion}

\subsection{HA spraying features by thermal spray techniques}

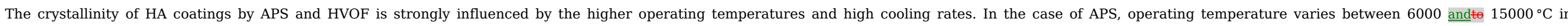

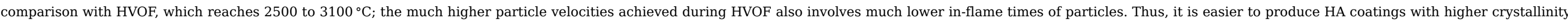

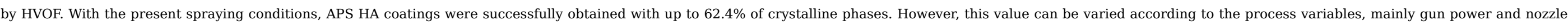

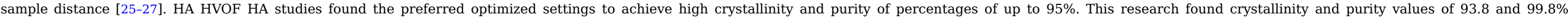



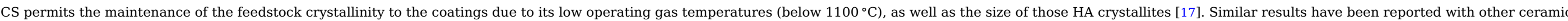
materials such as $\mathrm{TiO}_{2}$, by retaining the crystalline pure anatase phase [29].

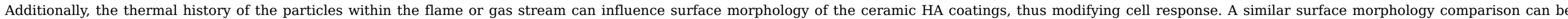

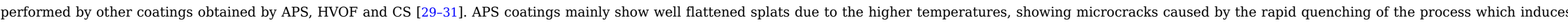

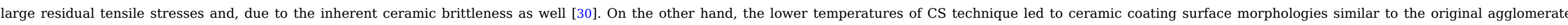

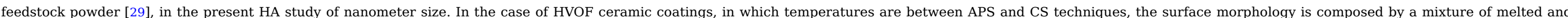
non-melted particles [30,31].

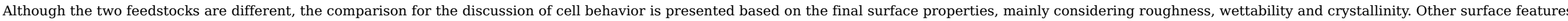



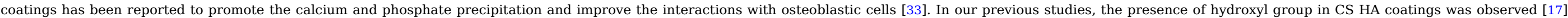

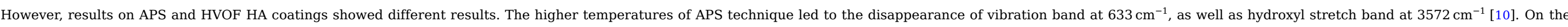

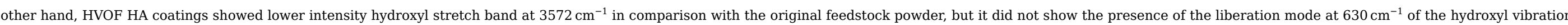
band [34].

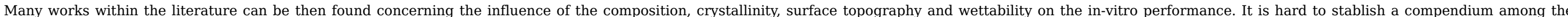
parameters, as all of them are related and involved on cell response. The discussion will be addressed trying to evaluate the characteristics that play a more predominant role based on surface features.

\subsection{Cell attachment and proliferation}

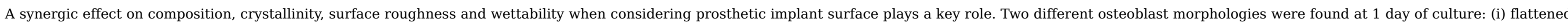

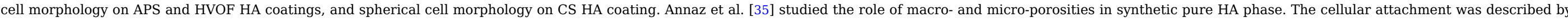

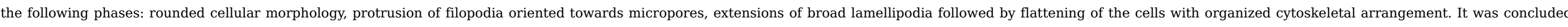

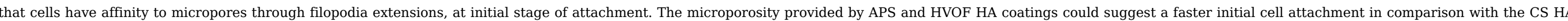

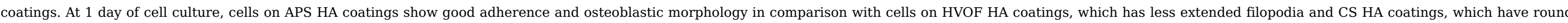

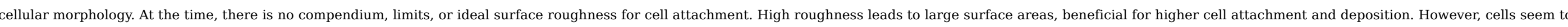

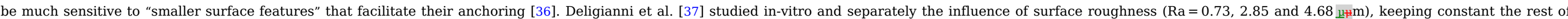
surface parameters. The study concluded that the increase of cell attachment enhances cell adhesion and proliferation. Also,a delayed increase of cell differentiation on rougher surfaces was reported.

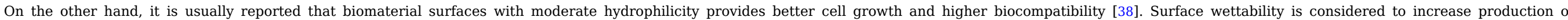



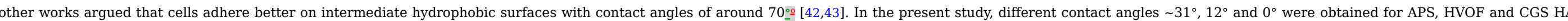

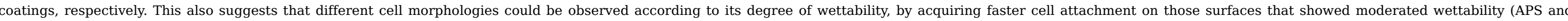




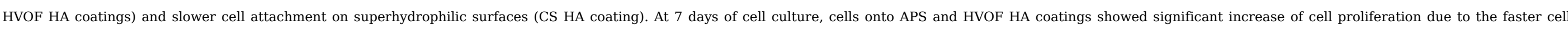
attachment, in comparison with rounded cells of CS HA coatings up to 7 days of cell culture.



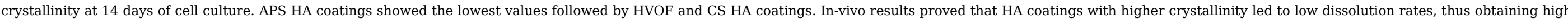

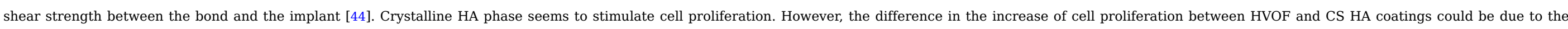
small crystal size [14].

\subsection{Cell differentiation}



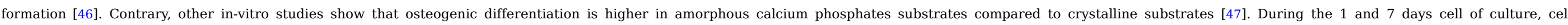



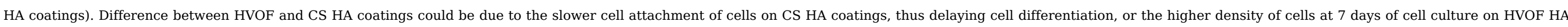
coatings. Thus, long period tests should be performed.

\section{Conclusions}

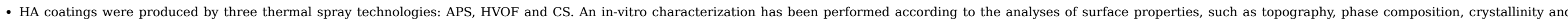



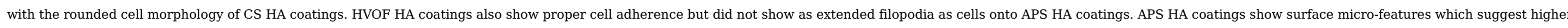
stimulation of cell anchoring. Therefore, moderate wettability is suggested to favour it.


of cell culture between both specimens is suggested to be influenced by HA crystal size on CS HA coatings.

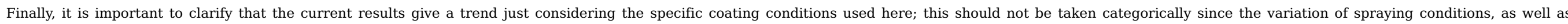
feedstock powder and substrate can change considerably the final properties of the coatings (surface roughness, wettability composition _.....), thus different cell response.

\section{Acknowledgments}

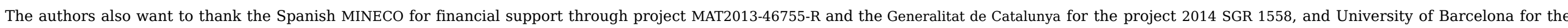

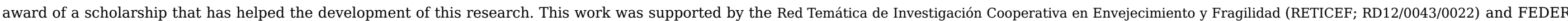
funds.

\section{References}

[1] L. Sun, C.C. Berndt, K.A. Gross and A. Kucuk, Material fundamentals and clinical performance of plasma-sprayed hydroxyapatite coatings: a review, J. Biomed. Mater. Res. 58, 2001, 570-592.

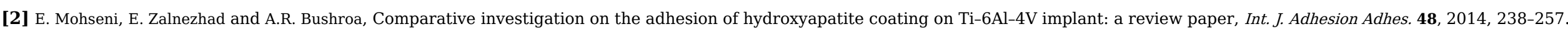

[3] Y.C. Tsui, C. Doyle and T. Clyne, Plasma sprayed hydroxyapatite coatings on titanium substrates Part 2: optimisation of coating properties, Biomaterials 19, 1998, 2031-2043.

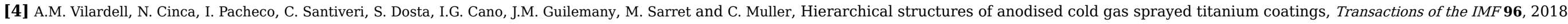
71-78, https://doi.org/10.1080/00202967.2018.1419625.

[5] F. Fazan and P.M. Marquis, Dissolution behavior of plasma-sprayed hydroxyapatite coatings, J. Mater. Sci. Mater. Med. 11, 2000, 787-792. 


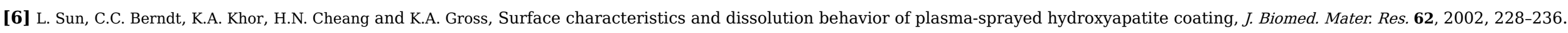

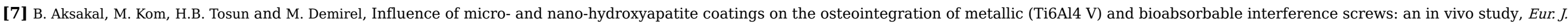
Orthop. Surg. Traumatol. 24, 2013, 813-819.

[8] K.A. Gross, C.C. Berndt and H. Herman, Amorphous phase formation in plasma-sprayed hydroxyapatite coatings, J. Biomed. Mater. Res. 39, 1998, 407-414.

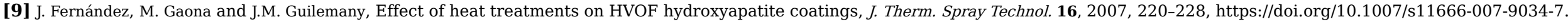

[10] M. Gaona and Thesis dissertation, Recubrimientos biocompatibles obtenidos por Proyección Térmica y estudio in vitro de la función osteoblastica, 2007, University of Barcelona.

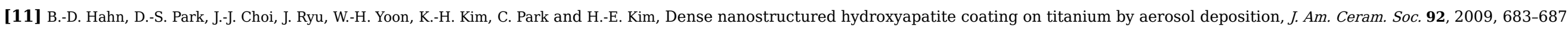

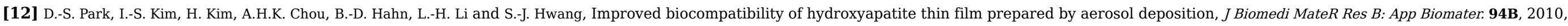
353-358.

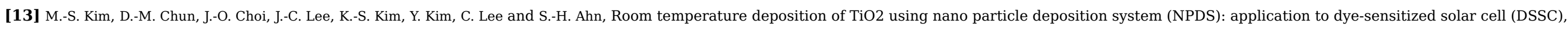
Int. J. Precis. Eng. Manuf. 12, 2011, 749-752.

[14] T.J. Webster, C. Ergun, R.H. Doremus, R.W. Siegel and R. Bizios, Enhanced functions of osteoblasts on nanophase ceramics, Biomaterials 21, 2000, 1803-1810.


surface roughnesses, Appl. Surf. Sci. 257, 2011, 7792-7799.

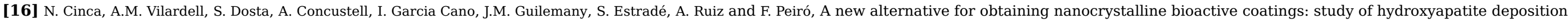
mechanisms by cold gas spraying, J. Am. Ceram. Soc. 99, 2016, 1420-1428.

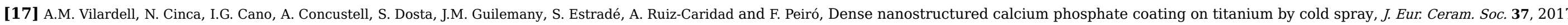
$1747-1755$.

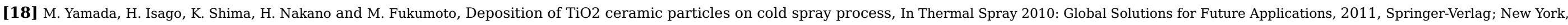
NY, . ISBN: 978-1-4419-8359-6172-176.

[19] D. Seo, M. Sayar and K. Ogawa, SiO2 and MoSi2 formation on inconel 625 surface via SiC coating deposited by cold spray, Surf. Coat. Technol. 206, 2012, 2851-2858.

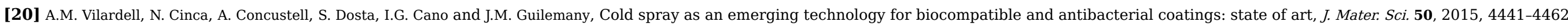

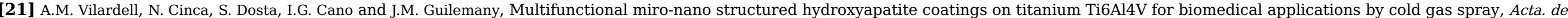
Protocolarización num. 809, 2015.

[22] J. Rodriguez-Carvajal Introduction to the Program FULLPROF: Refinement of Crystal and Magnetic Structures from Powder and Single Crystal Data

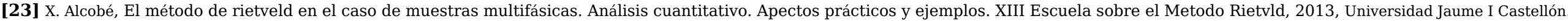

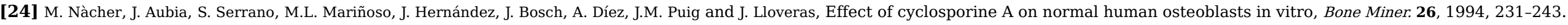

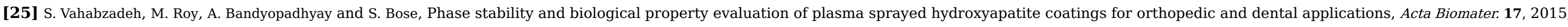
47-55.






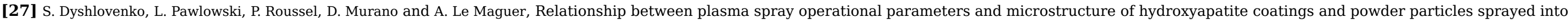
water, Surf. Coat. Technol. 200, 2006, 3845-3855.

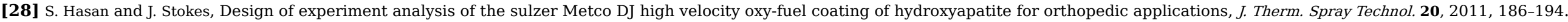

[29] G.-J. Yang, C.-J. Li, F. Han, W.-Y. Li and A. Ohmori, Low temperature deposition and characterization of TiO2 photocatalytic film through cold spray, Appl. Surf. Sci. 254, 2008, 3979-3982.

[30] G.-J. Yang, C.-J. Li, Y.-Y. Wang and C.-X. Li, Origin of preferential orientation of rutile phase in thermally sprayed TiO2 coatings, Mater. Lett. 62, 2008, 1670-1672.

[31] G.-J. Yang, C.-J. Li, Y.-Y. Wang and C.-X. Li, Dominant microstructural feature over photocatalytic activity of high velocity oxy-fuel sprayed TiO2 coating, Surf. Coat. Technol. 202, 2007, 63-68.

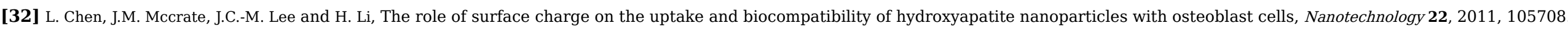

[33] P.A. Ramires, A. Romito, F. Cosentino and E. Milella, The influence of titania/hydroxyapatite composite coatings on in vitro osteoblasts behaviour, Biomaterials 22, 2001, 1467-1474.

[34] J. Fernández, M. Gaona and J.M. Guilemany, Effect of heat treatments on HVOF hydroxyapatite coatings, J. Therm. Spray Technol. 16, 2007, 220-228.

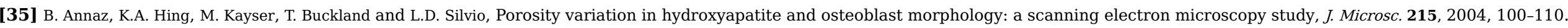


titanium cold gas spray coatings for biomedical applications, Mater. Sci. Eng. C 91, 2018, 589-596.


22, 2000, 87-96.

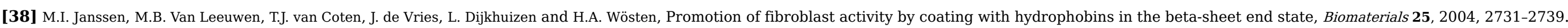

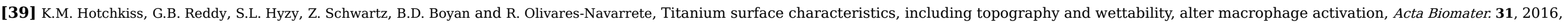
$425-434$.

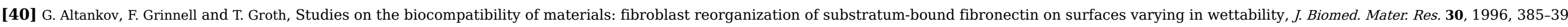

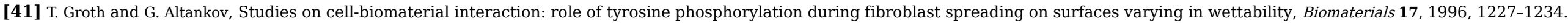

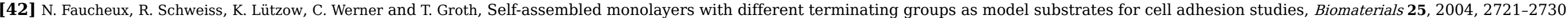

[43] Y. Ikada, Surface modification of polymers for medical applications, Biomaterials 15, 1994, 725-736.

[44] W. Xue, S. Tao, X. Liu, X. Zheng and C. Ding, In vivo evaluation of plasma sprayed hydroxyapatite coatings having different crystallinity, Biomaterials 25, 2004, 415-421.


cells, J. Mater. Chem. 17, 2007, 4690.

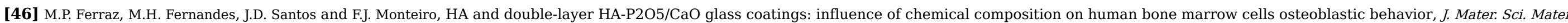
Med. 12, 2001, 629-638.

[47] S.H. Maxian, T. Di Stefano, M.C. Melican, M.L. Tiku and J.P. Zawadsky, Bone cell behavior on Matrigel-coated Ca/P coatings of varying crystallinities, J. Biomed. Mater. Res. 40, 1998, 171-179. 
Highlights

- In-vitro comparison of optimized HA coatings obtained by APS, HVOF and CS is evaluated.

- Osteoblastic cells showed a faster cell attachment onto APS and HVOF HA coatings than CS HA coatings.

- Cells start proliferating and differentiating after a proper cell attachment.

- Cell response has been discussed according to HA microstructure and surface parameters.

\section{Queries and Answers}

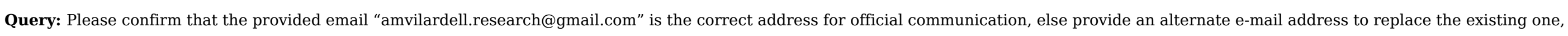
because private e-mail addresses should not be used in articles as the address for communication.

Answer: yes, correct

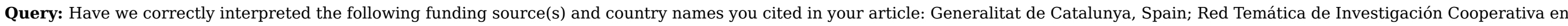
Envejecimiento y Fragilidad?

Answer: Yes

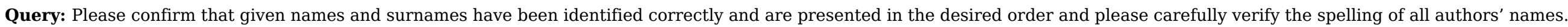
Answer: Yes

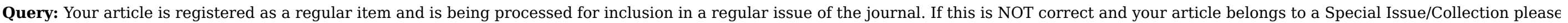
contact h.srinivasan.1@elsevier.com immediately prior to returning your corrections.

Answer: it is not part of any special issue 